\section{Cranks 0, Schoolboys 1}

\section{F. E. A. Johnson}

Fermat's Last Theorem. By Amir D. Aczel. Four Walls Eight Windows: 1996. Pp. 147. \$18, £12.99.

IN his public life, Pierre de Fermat was a successful lawyer, in his private life a mathematician. He published little, and was wont to jot down his discoveries as marginal notes. Some time in the $1630 \mathrm{~s}$, in his copy of Diophantus's Arithmetic, opposite a discussion of the solutions of the

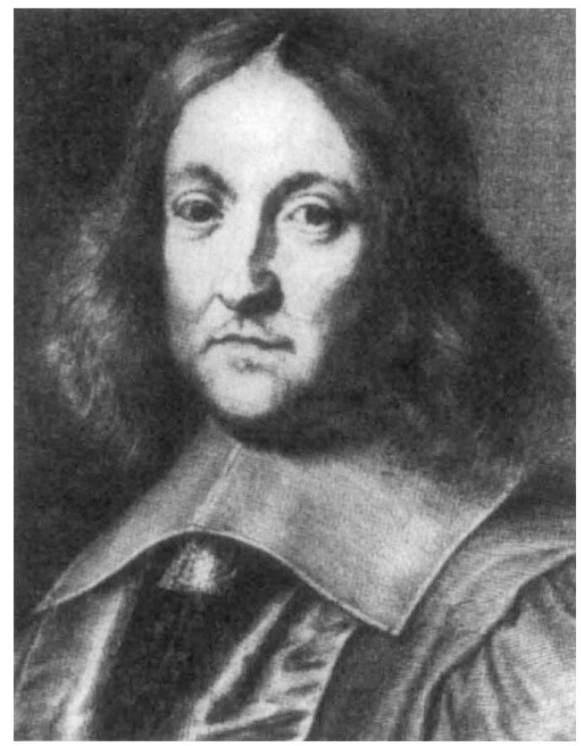

Fermat: puzzle took centuries to crack.

equation $x^{2}+y^{2}=z^{2}$ (which rises, of course, in connection with Pythagoras's theorem), Fermat observed that, by contrast, the only integer solutions to the corresponding equation $x^{n}+y^{n}=z^{n}$, with $n$ $\geqslant 3$, are the trivial ones, in which some term is zero. This is Fermat's last theorem. Fermat provided no proof, and thereafter generations of mathematicians tried, but failed, to find one. The problem became notorious for attracting cranks (and schoolboys), and the general view among mathematicians was that, in common with the flawed attempts in the nineteenth century by Lamé and Kummer, Fermat's presumed 'proof' was fallacious. Just over two years ago, however, the English mathematician Andrew Wiles seems finally to have produced a correct proof.

This is a book of two distinct halves. The author knows all the old stories recounted by Eric Temple Bell in Men of Mathematics (1937), and in the first half, dealing with the history, cannot resist retelling quite a few of them, regardless of their strict relevance to the matter in hand. Galois's duel, Cauchy's shameful treatment of Abel, even Euler and the
Konigsberg bridges are all trotted out. This is wonderful material, but the author fails to do it justice. In fact, he is on a hiding to nothing. In a book of this length, he cannot hope to compete with Bell's popular classic, which despite its sententious tone is still without a serious rival.

The author's approach is chatty rather than precise, and I found enough minor inaccuracies in what was familiar (Mordell was American, not English; the BolyaiLobatchevsky geometry on page 70 should be hyperbolic, not spherical) to give me qualms that the unfamiliar, although broadly correct, might not literally be so. For example, detecting a certain tendency towards 'imaginative reconstruction' of inessentials, I found myself worrying whether, in the conversation between Ribet and Mazur, Ribet was actually sipping cappuccino. Perhaps it was espresso. No matter, but it is that sort of book.

However, it is precisely at this point, in the final 44 pages, that the author comes into his own. There are broadly three separate phases. In the first, dealing with the priority dispute over what came to be known as the Taniyama-Shimura-Weil conjecture, he plunges headlong into controversy, and expresses himself in the most forthright manner on the rights and wrongs of the case. Some famous names come out of it badly mauled, but whether the reader can entirely appreciate this section without having witnessed the full spate of André Weil's acerbic wit is another matter.

The second deals with the stroke of genius of Gerhard Frey, and its vindication by Ribet. It is simply this: if $a^{p}+b^{p}=$ $c^{p}$ solves the Fermat equation then the elliptic curve

$$
y^{2}+x y=x^{3}+\frac{1-b^{p}-c^{p}}{4} x^{2}+\frac{b^{p} c^{p}}{16} x
$$

violates the Taniyama-Shimura conjecture, so that to prove Fermat it suffices to prove Taniyama-Shimura. Alas, the author misses the opportunity of writing down the Frey equation.

Finally, there is the truly dramatic section that describes Wiles's proof of the Taniyama-Shimura conjecture; his sevenyear self-imposed silence while developing his breakthrough techniques; his first and, as it turned out, premature announcement; the discovery of the gap in the proof; and the eleventh-hour rectification of the proof, just as he is about to abandon for good his apparently futile research.

Wiles's finished manuscript was published in Annals of Mathematics 142, 443-551 (1995). For those interested in the details, Wiles gives, in a long introduction, his own chronicle of the solution.

F. E. A. Johnson is in the Department of Mathematics, University College London, Gower Street, London WC1E 6BT, UK.

\section{Thought blocks}

\author{
Alan Mackay
}

The Quotable Einstein. Edited by Alice Calaprice. Princeton University Press: 1996. Pp. 269. \$16.95, £12.95.

QUOTATIONS are not epigrams, clever oneoff ripostes, neither are they simply significant extracts from some important author. Quotations are clichés, blocks of thought that can be used, indeed have been used, to encapsulate and drive home some idea better than the writer himself could manage. "Even ministers they ha'e been kenn'd, A rousing whid at times to vend, an' nail't wi' Scripture", to use one self-referentially.

Alice Calaprice, from two decades of editing the Einstein papers for publication, has collected significant extracts of Einstein's writing and has also inherited a collection of snippets made by Einstein's formidable secretary Helen Dukas, who was a jealous guardian of the reputation of the great man and one of the literary executors who refused me permission to quote an item from Einstein as being "unworthy".

The struggle for the literary inheritance, of which Freeman Dyson includes an interesting account in his foreword, is now amicably settled, and some 550 quotations by and about Einstein are presented for use.

Some have actually been tested as quotations by being quoted. Many others await this test, but all are provided with the most authoritative references to the Einstein archive. Some items come from the recently available private letters of Einstein to his wife, illuminating his personal marital difficulties but not more generally applicable, and some items illustrate the fact that Einstein shared many of the other failings of more ordinary people. Most of the original statements were in German, and only English translations are given here.

This is a useful collection, but the overall impact of 550 items is less than that of a dozen or two that have proved able to get about under their own power. We learn that the most famous quotation of 1921 . "Raffiniert ist der Herr Gott, aber boshaft ist Er nicht" ("The Lord God is subtle, but malicious he is not"), now engraved in stone at Princeton, was followed by "I have second thoughts. Maybe God is malicious" (to Valentin Bargmann, quoted in Einstein in America by J. Sayen; Crown, 1985), but this does not have the eternal impact of Galileo's "Eppur si muove".

Alan Mackay is in the Department of Crystallography, Birkbeck College, University of London, Malet Street, London WC1E 7HX, UK. 